\title{
Pleomorphic Adenoma of the Tongue Base: Case Report and Review
}

\author{
Luiz Augusto Nascimento ${ }^{1}$ Thais Gonçalves Pinheiro Vilela ${ }^{1,2}$ \\ 1 Division of Head and Neck Surgery, Department of Otolaryngology- \\ Head and Neck Surgery of the Brasilia University Hospital, Federal \\ University of Brasilia, Brasilia/DF, Brazil \\ 2 Department of Otolaryngology, The Medicine School of the \\ University of São Paulo, São Paulo/SP, Brazil \\ Address for correspondence Luiz Augusto Nascimento, MD, PhD, \\ Department of Otolaryngology-Head and Neck Surgery, Federal \\ University of Brasilia, SGAN 605, Av. L2 Norte, 70840-901 Brasilia/DF, \\ Brazil (e-mail: luizaugusto.hns@gmail.com).
}

Int Arch Otorhinolaryngol 2014;18:328-331.

\begin{abstract}
Introduction Pleomorphic adenoma, also known as mixed tumor, is the most common benign tumor of the major and minor salivary glands. The occurrence of pleomorphic adenoma of the tongue base is very rare, and very few cases have been reported in the literature.

Objective The authors present a rare case of pleomorphic adenoma of the tongue base and a review of the literature.

Case Report A 55-year-old woman had an extensive cervical mass, with little pain, from the submental level to the level below the hyoid bone. Fiberoptic endoscopic examination showed an extensive mass at the base of the tongue with considerable reduction in the airway. Magnetic resonance image scan revealed a contrast-enhancing mass of heterogeneous density over the base of the tongue of $8 \times 8 \times 7 \mathrm{~cm}$ and a reduction of

\section{Keywords}

- adenoma

- pleomorphic

- head and neck neoplasms

- tongue neoplasms

- oropharyngeal neoplasms the hypopharyngeal airway. Biopsy of the lesion was performed along with a tracheostomy due to the bulging tongue base and acute respiratory failure. Histologic examination with an immunohistochemistry study revealed a diagnosis of pleomorphic adenoma. The excision of the tumor was performed by a lateral pharyngotomy approach and the total mass was excised.

Conclusion The authors consider the rarity of this case and show that this is the 11th and the largest pleomorphic adenoma reported in the English-language medical literature.
\end{abstract}

\section{Introduction}

Pleomorphic adenoma, also known as mixed tumor, is the most common benign tumor of the major and minor salivary glands. ${ }^{1-3}$ Adenoid cystic carcinoma is the most common malignant tumor of this region, including the tongue. ${ }^{4}$ The literature indicates an overall ratio of $\sim 1: 6$ for benign/malignant lingual salivary gland tumors. ${ }^{2}$ More than $74 \%$ of the cases of pleomorphic adenoma arise in the major salivary gland, ${ }^{3}$ and it is predominantly found in the parotid gland. The palate is the most common site in the minor salivary glands. ${ }^{5}$ The occurrence of pleomorphic adenoma of the

received

February 26, 2013

accepted

May 3, 2013

published online

November 5, 2013
DOI http://dx.doi.org/

$10.1055 / \mathrm{s}-0033-1351683$ ISSN $1809-9777$. tongue base is very rare and very few cases have been reported in the literature. ${ }^{1,3}$

The authors report a rare case of pleomorphic adenoma of the tongue base causing dysphagia and dyspnea and present a review of the literature.

\section{Case Report}

A 55-year-old woman presented to the head and neck surgery service complaining of a cervical mass that had been growing for 3 years. At the moment of presentation, she had dysphagia, severe dyspnea, and difficulty in talking. She had

Copyright $\odot 2014$ by Thieme Publicações License terms Ltda, Rio de Janeiro, Brazil

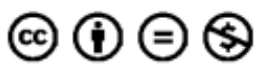




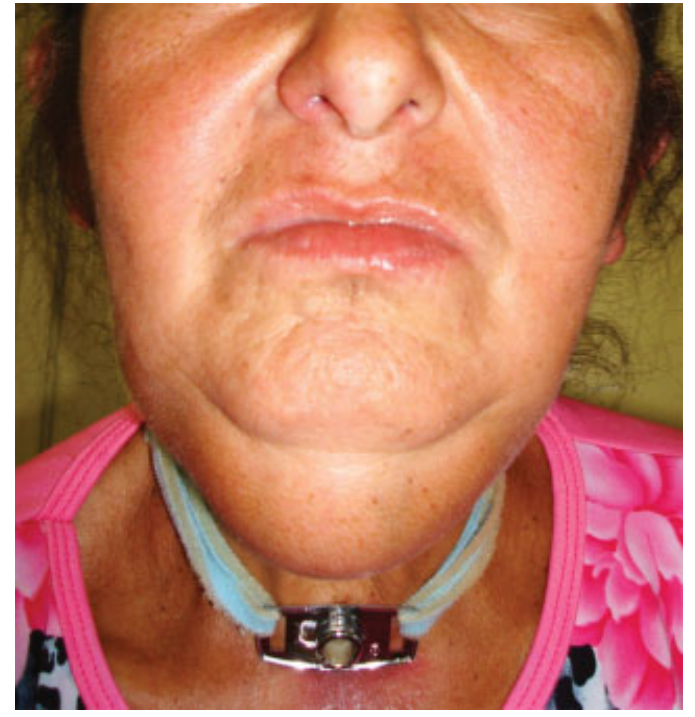

Fig. 1 Patient with an extensive submental mass of a firm elastic consistency.

important pain and eventual oral bleeding during deglutition. The patient reported smoking 15 cigarettes (without filter) per day for 30 years. There was no history of alcoholism and no visible pulsations could be seen in the mass.

Physical examination revealed an $\sim 8$ - $\mathrm{cm}$ mass in major diameter in the midline at cervical level I ( - Fig. 1). The patient presented lockjaw. Fiberoptic endoscopic examination showed a big mass at the tongue base with tissue necrosis and a substantial reduction of the airway.

Magnetic resonance image scan revealed a contrast-enhancing mass of $8 \times 8 \times 7 \mathrm{~cm}$ of heterogeneous density over the base of the tongue and a reduction of the hypopharyngeal airway (-Fig. 2).

Biopsy of the lesion was performed along with a tracheostomy due to the bulging tongue base and acute respiratory failure. A nasoenteral feeding tube was placed.

Histologic examination revealed the possibility that it was a mixed tumor of a malignancy type of pleomorphic carcinoma

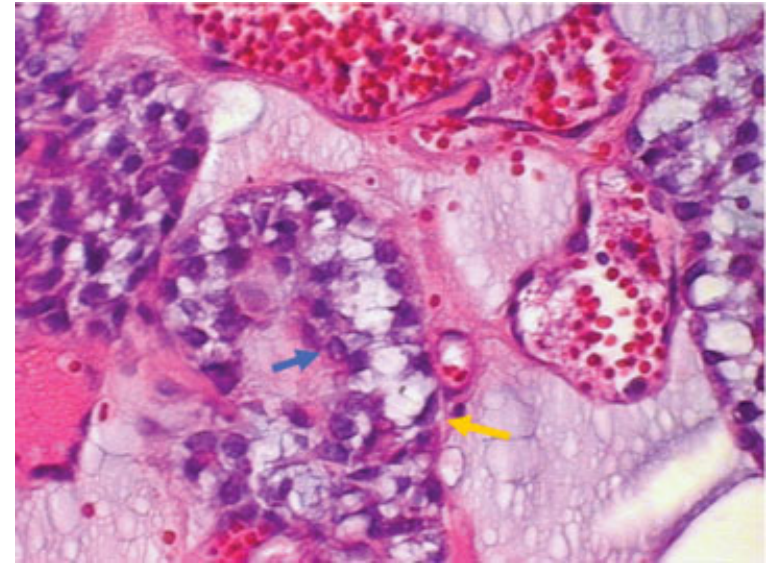

Fig. 3 Epithelial cells (blue arrow) and myoepithelial cells (yellow arrow; hematoxylin-eosin stain, original magnification $\times 400$ ).

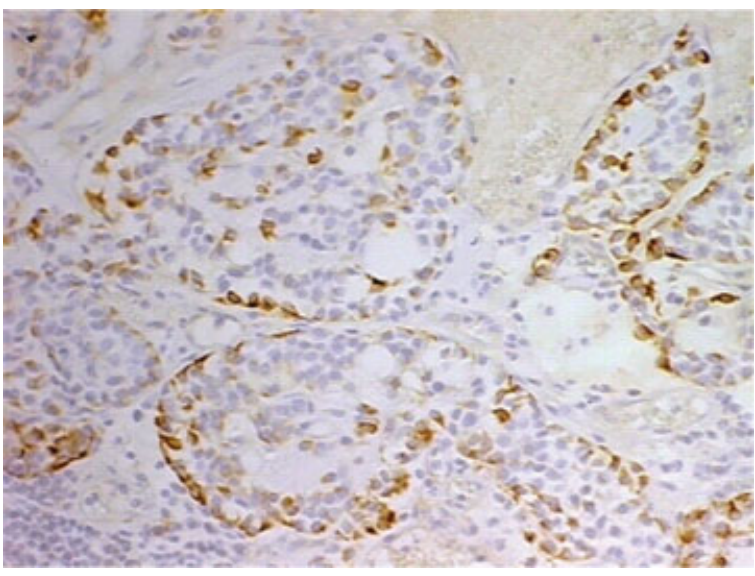

Fig. 4 Glial fibrillary acid protein immunoreactivity.

ex adenoma, low grade, without a definitive conclusion due to fragmentation of the material. Immunohistochemically, the cells were positive for glial fibrillary acid protein, favoring a diagnosis of pleomorphic adenoma.
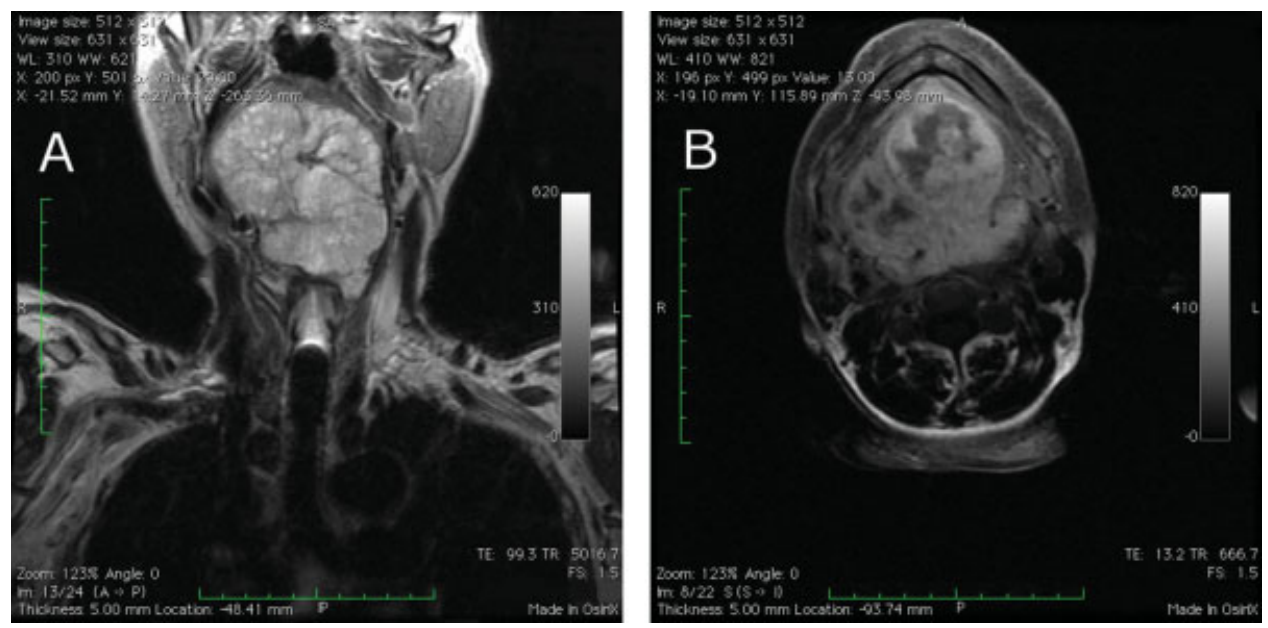

Fig. 2 Magnetic resonance image: coronal (A) and axial (B) cut showing extensive tumor mass at the base of the tongue with extension to the hypopharynx and cervical level I. 
Table 1 Reported cases of pleomorphic adenoma of tongue base

\begin{tabular}{|c|c|c|c|c|c|}
\hline Author(s) & Year & Age $(y)$ & Sex & Size $(\mathrm{cm})$ & Treatment \\
\hline Goepfert et al ${ }^{6}$ & 1976 & 39 & $\mathrm{~F}$ & - & Surgery and radiotherapy \\
\hline Grewal et al ${ }^{7}$ & 1984 & 35 & M & 4 & Surgery \\
\hline Deitmer and Stoll ${ }^{8}$ & 1985 & 29 & M & $2 \times 3$ & Surgery \\
\hline Banerjee $^{9}$ & 1987 & 32 & M & $2 \times 3$ & Surgery \\
\hline Magliulo et al ${ }^{10}$ & 1996 & 82 & $F$ & $3 \times 4$ & Surgery \\
\hline Gupta et $a l^{2}$ & 1997 & 50 & $\mathrm{~F}$ & $1.75 \times 2.5$ & Surgery \\
\hline Yoshihara and Suzuki ${ }^{3}$ & 2000 & 87 & $\mathrm{~F}$ & $2 \times 3$ & Surgery \\
\hline Berry et al ${ }^{1}$ & 2004 & 66 & $\mathrm{~F}$ & $2 \times 2$ & Surgery \\
\hline Ghosh et al ${ }^{4}$ & 2011 & 40 & $\mathrm{~F}$ & $2 \times 2.5$ & Surgery \\
\hline Bansal et $\mathrm{al}^{5}$ & 2012 & 24 & $\mathrm{~F}$ & $3 \times 3$ & Surgery \\
\hline Present case & & 55 & $\mathrm{~F}$ & $8 \times 8$ & Surgery \\
\hline
\end{tabular}

Subsequently, excision of the mass was performed under general anesthesia using a lateral pharyngotomy approach, and the total mass was excised with a clear cleavage plan with the neighboring structures. The histologic examination of the mass confirmed the diagnosis (-Figs. 3 and $\mathbf{4}$ ). The postoperative period was uneventful and the patient was successfully decannulated on the 50th postoperative day and she is free of disease to date.

\section{Discussion}

The majority of salivary gland neoplasms are benign and pleomorphic adenoma is the most common. Tumors of the salivary glands comprise $3 \%$ of all neoplasms. ${ }^{4}$ The incidence of salivary gland neoplasms in minor glands varies from 9 to $22 \%$. Approximately $8 \%$ of pleomorphic adenomas involve the minor salivary glands. The majority involve the palate, followed by the lips and maxillary sinus. ${ }^{1,3,5}$ Involvement of the base of the tongue is rare. ${ }^{1,2}$ Malignant tumors such as adenocarcinoma, adenoid cystic carcinoma, and mucoepidermoid carcinoma involve the tongue more frequently. ${ }^{1-3}$

Only 10 other cases of pleomorphic adenoma involving the tongue base have been reported in the English-language literature (-Table 1). Patients' ages ranged from 24 to 87 years old (average of 49) and the male-to-female ratio was 3:8, including the present case.

These tumors are slow-growing and sometimes the treatment may be late. ${ }^{2}$ Dysphagia is the most frequent initial symptom, and some of the tumors are detected on routine physical examinations by general practitioners. ${ }^{3,4}$

Treatment is primarily surgical irrespective of the site of origin. Resection of the tumor with an adequate margin is essential to avoid recurrence, although these tumors are well encapsulated. ${ }^{1}$ Recurrence is uncommon and may be attributed to partial excision or a multifocal origin of the tumor. ${ }^{2,4}$ Some studies report a recurrence rate of $6 \%$ in patients with benign minor salivary gland tumors. ${ }^{1}$ Surgical approaches vary according to the size and site of the tumor: transoral, combined transoral-transcervical, transmandibular, and transpharyngeal. Transmandibular can be lip splitting, mandibular swing, or median labiomandibular glossotomy. Transpharyngeal can be either suprahyoid or transhyoid pharyngotomy or by lateral pharyngotomy. ${ }^{5}$ When the tumor is malignant with extensive invasions into surrounding tissues, the latter two approaches are recommended. ${ }^{3}$

The origin of the pleomorphic adenoma is myoepithelial cells and intercalated duct cells. ${ }^{2}$ The histopathologic appearance of a pleomorphic adenoma is mainly composed of epithelial and myoepithelial elements, with a variety of patterns ending up embedded in mucopolysaccharide stroma. Fibrosis of the surrounding salivary parenchyma forms a capsule, usually false. ${ }^{1}$ Pleomorphic adenoma of the minor salivary gland is known to have more cellular and fewer mesenchymal components. In cases of the elderly, malignant degeneration to carcinoma ex pleomorphic adenoma must be taken into consideration. ${ }^{3}$

\section{Conclusion}

This is the 11th case of pleomorphic adenoma involving the tongue base that has been reported in the English-language literature and the biggest one.

\section{References}

1 Berry S, Tay H, Puentes CP. Pleomorphic adenoma of the base of the tongue. Ear Nose Throat J 2004;83:646-648, 648

2 Gupta AK, Singhal SK, Mann SBS, Bapuraj JR, Saran RK. Pleomorphic adenoma presenting as a base of tongue mass. J Laryngol Otol 1997; $111: 1177-1178$

3 Yoshihara T, Suzuki S. Pleomorphic adenoma of tongue base causing dysphagia and dysphasia. J Laryngol Otol 2000;114:793-795

4 Ghosh SK, Saha J, Chandra S, Datta S. Pleomorphic adenoma of the base of the tongue: a case report. Indian J Otolaryngol Head Neck Surg 2011;63(Suppl 1):113-114

5 Bansal S, Kalsotra G, Mohammed AW, Bahl A, Gupta AK. Pleomorphic adenoma of base of tongue: is midline mandibulotomy necessary for approaching benign base tongue lesions? Case Rep Otolaryngol 2012;2012:851501 
6 Goepfert H, Giraldo AA, Byers RM, Luna MA. Salivary gland tumors of the base of the tongue. Arch Otolaryngol 1976;102: 391-395

7 Grewal DS, Pusalkar AG, Phatak AM. Pedunculated pleomorphic adenoma of the tongue base manifesting with dysponea. A case report. J Laryngol Otol 1984;98:425-427
8 Deitmer T, Stoll W. [Rare tumors of the base of the tongue and their therapy]. HNO 1985;33:366-369

9 Banerjee S. Benign pleomorphic adenoma of the base of the tongue. J R Coll Surg Edinb 1987;32:164-165

10 Magliulo G, Terranova G, Cristofari P. Pleomorphic adenoma of the tongue base. Ann Otol Rhinol Laryngol 1996;105:835-837 